\title{
Postcricoid Squamous Cell Carcinoma
}

National Cancer Institute

\section{Source}

National Cancer Institute. Postcricoid Squamous Cell Carcinoma. NCI Thesaurus. Code C8185.

A squamous cell carcinoma of the hypopharynx that arises from the postcricoid region. 